\title{
DIARIO Y LOS CUADERNOS DE SEGOVIA: LA MEMORIA PÓSTUMA DE LUIS FELIPE VIVANCO
}

\author{
Joaquín JUAN PENALVA \\ Universidad de Alicante
}

\section{RESUMEN}

Luis Felipe Vivanco (San Lorenzo del Escorial, 1907-Madrid, 1975), uno de los poetas que, durante la inmediata posguerra, participó activamente en las páginas de Escorial (1940-1950), revista madrileña auspiciada por la joven intelectualidad falangista, escribió, a lo largo de toda su vida, un diario íntimo que abarca desde 1941 hasta 1975. En estas páginas se presenta una aproximación a la figura de este poeta-arquitecto y, sobre todo, a su escritura autobiográfica, de la cual, hasta ahora, sólo se ha publicado una mínima parte, la incluida en Diario (1983) y Los cuadernos de Segovia (1991).

Palabras clave: Vivanco, poeta, escritura autobiográfica, diario.

\section{ABSTRACT}

These pages focuse on the poet-architect Luis Felipe Vivanco, and especially on his autobiographical writing, an intimate diary that he wrote during all his life. Only a tiny part of this diary, that includes the period between 1941 and 1975, has been published up to the moment in Diario(1983) and Los cuadernos de Segovia (1991).

Key words: Vivanco, poet, autobiographical writing, diary.

Durante los años de la tesis, dediqué mis esfuerzos a estudiar las páginas de la revista Escorial, donde se reunía una serie de poetas que, ya desde el primer año de carrera, me habían resultado atractivos tanto desde un punto de vista biográfico como literario. Mi intención inicial era el estudio pormenorizado de alguno de aquellos autores (Luis Rosales, Leopoldo Panero, Dionisio Ridruejo o Luis Felipe Vivanco), a quienes, en ocasiones, la crítica se ha referido como «grupo Rosales» 
o de Escorial ${ }^{1}$. Esta denominación fue precisamente la que me puso tras la pista de la revista madrileña, de la que dichos poetas, junto a Pedro Laín Entralgo y otros intelectuales del período, habían sido los impulsores principales.

Recuerdo que, al principio, llegué a Escorial con la idea preconcebida de que aquellos poetas merecían más atención de la que habían recibido, y que, si habían sido preteridos, era por cuestiones puramente extraliterarias. Pronto descubrí, sin embargo, que aquello no era cierto para el caso de Panero, Rosales y Ridruejo, cuyas respectivas obras habían merecido varias monografías cada una; sí, en cambio, para el de Vivanco, que parecía eclipsado, sobre todo, por la presencia de Rosales. Quizás hubiera debido dedicar todos mis esfuerzos a la figura y a la producción de Vivanco, pero entonces ya me encontraba atrapado en las redes de Escorial, donde encontré, al menos in fieri, buena parte de la cultura española de posguerra. Hoy, al volver sobre Vivanco, regreso, pues, a una deuda pendiente con un poeta que no obtuvo demasiado reconocimiento en vida y con el que la historia de la poesía española todavía tiene una cuenta pendiente.

Hay centenarios que se celebran con grandes fastos institucionales y una amplia panoplia de actividades; otros, en cambio, apenas se recuerdan y pasan casi inadvertidos, muy discretamente, por las páginas de las revistas literarias y de los suplementos culturales. En ocasiones, dichos centenarios tienen mucho que ver con el mecenazgo de universidades, ayuntamientos, diputaciones o cajas de ahorros, y para eso es necesario ser de algún sitio: no sólo haber nacido en aquel lugar, sino haber dejado allí algo tangible, como una casa, una biblioteca, una

1. Los poetas del grupo Escorial se iniciaron en la poesía durante los años de la República y publicaron sus primeros libros en la inmediata preguerra. Todos ellos pertenecen a una de las promociones más polémicas de las letras españolas, la del 36; sin embargo, ellos no conforman la totalidad de la promoción, sino sólo una parte muy específica. Hay un buen número de etiquetas que se aplican indistintamente a la poesía que estos autores cultivaron durante la posguerra. Así, es frecuente la de realismo intimista o cotidiano, pero también la de poesía arraigada, acuñada por Dámaso Alonso, y la de poesía de la intrahistoria, establecida por García de la Concha. No es éste el lugar apropiado para discutir la pertinencia del marbete generación del 36, pero lo cierto es que el grupo Escorial, cuyos miembros habían entablado contacto en el Madrid de los años treinta, habría de configurarse como tal durante los años de la guerra, en Pamplona, alrededor de la revista Jerarquía; y, ya en un segundo momento, en Burgos, a las órdenes del a la sazón Director General de Propaganda, Dionisio Ridruejo. Ese grupo encontraría acomodo tras la guerra en la redacción de la revista Escorial. José Luis L. Aranguren, uno de los protagonistas de aquel episodio, escribe a este particular: «Entre tanto establecí una relación de amistad estrecha con Luis Felipe Vivanco, a quien conocí en casa de d'Ors, y con Luis Rosales, por la revista Escorial. A través de ellos, conocí a Leopoldo Panero. Los cuatro éramos de la misma edad casi exactamente, Luis Felipe un poco mayor, Luis Rosales un año menor que Panero y que yo. Con ellos y conmigo intimó José María Valverde, bastante más joven que nosotros. Las reuniones en la casa de Juana Mordó facilitaron el asiduo contacto entre nosotros, también con Pedro Laín y con otros escritores y artistas. Durante algunos años constituimos un grupo literario, ya que no la 'generación del 36' que, en el supuesto de que exista, comprendería a muchos escritores más, y no, en cambio, a José María Valverde. La función que dentro del grupo asumí fue algo así como la de su crítico» (Aranguren, 1969: 63-64).

Anales, 21, 2009, pp. 85-99 
familia, una placa... Quien no es de ningún sitio o vivió en diversos lugares, al final, no será recordado en ninguno. El caso de Luis Felipe Vivanco (San Lorenzo del Escorial, 1907-Madrid, 1975) no es tan extremado, pero su centenario ha pasado sin revuelos ni congresos ${ }^{2}$, acaso porque su figura ha quedado oculta tras un marbete o confundida entre otros autores de su misma cuerda estética a los que se le ha asociado sin matices. Es en la familia, en los amigos y en los asuntos cotidianos donde estos autores encuentran los materiales necesarios para la creación. Y no se trata sólo, y acaso ni siquiera preferentemente, de una concepción estética, sino de una actitud vital que ha de vincularse a la idea de desengaño o desencanto en que se resuelve el encuentro de las circunstancias históricas con las expectativas personales. Estos poetas falangistas habían sido los vencedores de la guerra, pero en la inmediata posguerra, al chocar con los resortes más reaccionarios del régimen que ellos mismos habían contribuido a instaurar, cayeron en la más profunda desilusión. Todos ellos pueden inscribirse dentro de ese «realismo intimista trascendente» acuñado por el mismo Vivanco (1950: 18), pero cada uno tiene una voz propia.

De profesión arquitecto, carrera que acabó en 1932 -aunque después se matriculó en la Facultad de Filosofía y Letras, donde conoció a Luis Rosales-, Vivanco se mantuvo siempre alejado de honores literarios y cargos académicos, algo que, al final, le ha resultado muy caro, pues ha sumido su obra en el limbo editorial. La crítica ha coincidido en señalar que su poesía es de una profundidad poco común, aun cuando beba de las realidades más cotidianas: búsqueda de refugio en lo más íntimo, en lo más verdadero y entrañable del ser. Ni siquiera en el día de su muerte tuvo fortuna, pues falleció a las cuatro y media de la madrugada del 21 de noviembre de 1975; su deceso, por tanto, no existió más que para unos pocos allegados, ya que el resto del país estaba pendiente de la muerte

2. Tan sólo la Imprenta Artesanal del Ayuntamiento de Madrid, ciudad en la que el poeta vivió la mayor parte de su vida, ha logrado paliar, siquiera parcialmente, ese olvido con la publicación de un estuche en el que se incluye una excelente monografía, Luis Felipe Vivanco: contemplación y entrega, de Rafael Alarcón Sierra, y una cuidada antología de su obra poética, con edición de Margot Vivanco e ilustraciones de Gustavo Torner. Quizás parezca un homenaje modesto, pero no lo es, ni mucho menos, sobre todo si se tiene en cuenta la escasa trascendencia editorial que ha tenido la obra de Vivanco en los últimos años. Hasta 2001, los lectores únicamente podían acceder a su poesía a través de dos antologías, la de Alianza (1976) y la de Visor (1998), útiles pero insuficientes. En 2001, con la publicación de los dos primeros volúmenes de sus obras escogidas (Madrid, Trotta), parecía que iba a corregirse esa tendencia, pero se interrumpió el proyecto -que incluía dos nuevas entregas, ensayo y crítica literaria-, de modo que muchos de los libros de Vivanco sólo existen en los catálogos de viejo y en las librerías de lance. En fin, un capricho más de nuestra historia literaria, que no debería permitirse el lujo de prescindir de alguien como Vivanco, un poeta hondo y sereno, que concilia vanguardismo y realismo, autor de títulos tan valiosos como Continuación de la vida (1949), El descampado (1957) o Lecciones para el hijo (1961); pero también un excelente crítico, como demostró en Introducción a la poesía española contemporánea.

Anales, 21, 2009, pp. 85-99 
de Franco y de las consecuencias políticas que acarrearía. Este final es una buena imagen de la vida de Vivanco, en la que la idea del fracaso estuvo presente de forma constante, pues tanto su figura como su obra quedaron siempre a la sombra de otros. José-Carlos Mainer lo consideraba el dioscuro de Rosales; Francisco Umbral lo equiparaba al cuarto de los hermanos Marx; y, sin embargo, su obra ha llegado, en mayor o menor medida, hasta algunos poetas españoles contemporáneos, desde Antonio Moreno hasta Alberto Santamaría, por citar sólo dos autores que han manifestado de forma explícita su querencia por la poesía de Vivanco.

A pesar de la reciente monografía de Rafal Alarcón Sierra y de la edición de la poesía completa de Pilar Yagüe y José Ángel Fernández Roca, nuestra historia literaria todavía le debe mucho a Luis Felipe Vivanco. Anna Caballé, en fechas próximas a su centenario, lo recordaba así:

Vivanco no fue un escritor con suerte: con enormes sacrificios personales, mantuvo al margen su rentable profesión (era arquitecto y de él dependió, por ejemplo, la ejecución de la Colonia El Viso en los años cuarenta), para centrar todo su esfuerzo en la poesía, su verdadera y profunda vocación. Y junto a ella, sus trabajos de crítica literaria (Moratín y la Ilustración Mágica, 1972) o sobre pintura dibujan un mundo de intereses siempre coherente con sus preocupaciones: el arte como refugio, la dialéctica acción/sentimiento, la actitud contemplativa ante la vida...

Sin embargo, su notoriedad intelectual no ha conseguido imponerse a los condicionantes políticos. Sobre él pesa la losa de poeta falangista, la inercia de hombre del Régimen, sin reparar en que vivió siempre culpabilizado por su parte de responsabilidad en la instauración del franquismo, imponiéndose un exilio interno muy riguroso que le mantuvo voluntariamente al margen de prebendas oficiales. Su callada rebeldía, su rechazo al franquismo, su dignidad personal apenas han sido consideradas (Caballé, 2007: 10).

Más allá de su obra poética, de su crítica de arte y de literatura y de su participación en la elaboración de numerosos catálogos de exposiciones, Vivanco practicó una suerte de literatura autobiográfica que quedó plasmada en unos diarios íntimos y unos cuadernos personales de estío. Sólo una pequeña parte de esa producción ha visto la luz hasta la fecha, la editada póstumamente en los volúmenes Diario (1946-1975) (1983) y Cuadernos de Segovia (Estancias y vagancias) (1991). Frente a las memorias públicas, y muchas veces polémicas, de sus compañeros de generación, como las de José Luis López Aranguren, Pedro Laín Entralgo o Dionisio Ridruejo, Vivanco ofrece tan sólo retazos de una vida interior muy rica, si bien hasta nosotros han llegado únicamente aquellos fragmentos que, seleccionados por su familia, se ocupan, no de su dimensión interior, sino de su entorno social y literario, de su dimensión más pública.

Creo que la idea de fracaso y la de derrota es la que planea de una forma más constante sobre la biografía, los cuadernos y los diarios de Vivanco, ya que no compatibilizó nunca bien su trabajo como arquitecto con su dedicación a 
la poesía. De hecho, cuando, en 1972, se aproximó a la historia de la literatura española del siglo XVIII con la monografía Moratín y la Ilustración mágica, lo que estaba buscando en Moratín era un trasunto literario, una figura con la que poder compararse y equipararse:

A Moratín hay que estimarlo, creo yo, por su fracaso como gran escritor. Cervantes
fue también un escritor fracasado en su vida, pero no en su obra, ni siquiera en su
poesía o en su teatro. Moratín fue escritor fracasado en su vida y en su obra, con
excepción tal vez de un par de comedias y algunas traducciones. Cervantes, a su
tamaño, es escritor a caballo entre el XVI y el XVII, sin entrar de lleno en el barroco.
Moratín, al suyo, es escritor a caballo entre el XVIII y el XIX, sin entrar en el roman-
ticismo, ni siquiera en ese momento final de la Ilustración tan extraordinario, al que
podríamos calificar de mágico (Vivanco, 1972: 14-15).

Efectivamente, para Vivanco, Moratín sólo existe en la prosa de sus diarios, cuadernos de viajes y cartas. Era un autor perfectamente dotado para la lírica en una época en que ésta estaba atenazada por el didactismo y la sátira, contagiada irrevocablemente por el racionalismo, lo que produjo un descenso inevitable de la imaginación poética: «La vida de Moratín, en definitiva, es eso: renuncia. No sabemos si en él-que dejó de escribir para el teatro obras originales suyas después del estreno de El sí de las niñas- hay un poeta cómico fracasado; sabemos que hay en él, frustrado, un gran poeta lírico» (Vivanco, 1972: 56).

En este sentido, Vivanco descubre a un nuevo Moratín, pero se inventa otro, el que pudo haber sido de haber actualizado muchas de las potencias que en él se encontraban. Eso, que en historia literaria no vale para nada, sí le sirve a Vivanco para verse reflejado en un espejo del pasado. Difícilmente se puede entender Moratín y la Ilustración mágica si no se recurre a la biografía de Vivanco, que se ha encontrado a sí mismo reflejado en el dramaturgo madrileño. Si hay una preocupación constante a lo largo del Diario de Vivanco, según veremos, es la de armonizar vida y obra:

Mi obra consiste en pertenecer, no en hacer. Por el hacer, las cosas le pertenecen a uno. Pero yo me entrego al paisaje, a María Luisa, a las niñas. Pertenezco a estas realidades. ¿Soy un místico? Por eso, no me importa mi hacer profesional, al contrario, es casi el único que hago, porque no pongo vida en él, sino defensa de la vida. Pongo mi corazón exclusivamente en mi vida, y sólo a través de ella en su defensa. ¿Y mi obra poética? Forma parte de mi vida. No es mi profesión. De aquí lo importante que haya una profesión distinta, bien diferenciada. No sólo desde el punto de vista crematístico, sino también desde el vital y afectivo. Pero viviendo así, tan atenido exclusivamente a la vida, se corre el peligro de caer en lo enfermizo, que es reconocible por su infecundidad (Vivanco, 1983: 48).

Esa idea de fracaso se puede rastrear en muchos libros y poemas de Vivanco, como ya se ha visto a propósito de Moratín y la Ilustración mágica. Así ocurre, por ejemplo, en Lecciones para el hijo (1961) o Los ojos de Toledo (1953). Sobre esta úl-

Anales, 21, 2009, pp. 85-99 
tima, José Ángel Fernández Roca ha escrito lo siguiente en La palabra vivida: «Los ojos de Toledo ronda la ficción narrativa; proviene de Bécquer y los románticos, con su prosa poética y su demorado avance argumental; ahora bien, dentro de su discutible adscripción genérica, predomina el discursos autobiográfico, por muy literaturizado que esté: son las 'memorias' de Vivanco adolescente, envueltas en una atmósfera de misterio» (Fernández Roca, 2001: 48).

También encontramos autodiégesis en el volumen póstumo Prosas propicias, publicado en 1976, con prólogo de Gerardo Diego, que, en realidad, era un libro misceláneo de prosas poéticas, en el que Vivanco se aproximaba a una literatura satírica y epigramática que no había cultivado nunca. Hubo por parte del autor un intento de recopilación y publicación del volumen, tal como se señala en el epílogo del mismo: «Al morir Luis Felipe Vivanco en la madrugada del 21 de noviembre de 1975, dejó sin terminar y seleccionar este poemario que había ido escribiendo durante los últimos años y meses de su vida» (Vivanco, 1976:181). De las tres partes que se conservan -Prosas líricas, Sátiras y Prosas de amistad-, la última es, sin duda, la que más se atiene a una memoria personal de lo vivido, pues hay en sus páginas un auténtico muestrario de amistades, lecturas y homenajes. Éstos son algunos de los nombres convocados: Luis Rosales -a propósito de su $60^{\circ}$ cumpleaños-, José Antonio Muñoz Rojas, Arturo Serrano Plaja, Celso Emilio Ferreiro, Félix Grande, José Herrera Petere, Gerardo Diego, Melchor Fernández Almagro, J. V. Foix, Jorge Guillén, Vicente Aleixandre, Dámaso Alonso, José Bergamín -su tío-, Dionisio Ridruejo, José María Valverde - con motivo de su renuncia a la Cátedra de Estética de la Universidad de Barcelona; Valverde era, además, cuñado de Vivanco, casado con una hermana de María Luisa Gefaell-y Pablo Neruda -a propósito de su muerte-. Es posible que Prosas propicias contenga más memoria de la que encontramos en otros libros del autor, pero no deja de ser un volumen poético que, si se ha traído aquí, es para dejar constancia de las lecturas y relaciones que mantuvo Vivanco en los últimos años de su vida.

Ahora bien, donde encontramos de una forma palmaria la memoria póstuma de Luis Felipe Vivanco es en los dos volúmenes arriba mencionados, a los que atenderemos por orden de publicación. Antes, sin embargo, sería necesario establecer una pequeña diferenciación entre textos de cariz autobiográfico que fueron escritos para ser publicados -es el caso de las autobiografías y de los libros de memorias- y aquellos otros que, en principio, no iban a ser publicados, pero se publicaron tras la muerte del autor -diarios, cartas y demás documentos de carácter íntimo-. Lo más interesante de estos últimos es que se fueron escribiendo a lo largo de la vida del autor y no hay en ellos el grado de autodefensa o autojustificación que suele haber en los libros de memorias y autobiografías, 
que, no en vano, son recreaciones del pasado desde un presente, aunque el autor en cuestión pueda valerse de cartas o diarios. Ésa es la gran virtud de los diarios y cuadernos de Vivanco, que no fueron escritos para el público, sino para dar cauce a la propia intimidad. El volumen de cuadernos y diarios escritos por Vivanco es enorme, pero hasta los lectores sólo ha llegado una mínima muestra, tal como ha señalado Anna Caballé:

Su interesantísimo diario, escrito entre 1941 y 1975, a lo largo de 34 años. Su hija Soledad preparó a la muerte del poeta una antología del mismo [...], excelente, pero que no puede dar idea del alcance de su conmovedora escritura, que sigue inédita. Un total de 216 cuadernos organizados por meses y cuyo texto mecanografiado (disponible gracias a la labor emprendida por su esposa a la muerte del poeta) ocupa 24 volúmenes. Vivanco escribía en blocs de pequeño tamaño que llevaba siempre encima. En ellos iba anotando ideas, lecturas, preocupaciones económicas, estados de ánimo, convicciones religiosas, su oposición a Franco y a la "España sucedánea" con él constituida, su rechazo al boato del catolicismo, que ve como una mamarrachada, su amor a la familia, al paisaje... "¿Qué será de estos cuadernos?”, se pregunta cerca del fin. " ¿Tiene uno derecho a dejar tan detallada su vida interior?". Porque, en efecto, dudo que nuestra literatura disponga de un diario comparable a éste (Caballé, 2007: 10).

Hablamos, pues, de un texto que desconocemos casi por completo, del que sólo nos han llegado algunas migajas, y que, sin duda, convendría recuperar, anotar y editar, pues puede suponer algo así como una memoria personal -la de Vivanco, claro- de casi todo el franquismo, escrita por alguien que contribuyó modestamente a instaurarlo, pero que enseguida cayó en el desencanto. Hasta que llegue ese momento, nos conformaremos con este pequeño avance, del que ya se ocuparon, entre otros, José Luis Cano y Jaime Siles. Para el primero, Vivanco fue «[u]n español desengañado, como tantos, a quien amargó y destruyó la España injusta y esperpéntica que se vivió bajo los cuarenta años de Franco. Su Diario es quizá uno de los testimonios más patéticos de ese dolorido desengaño» (Cano, 1984: 9).

Lo que conocemos del diario de Vivanco se publicó en 1983 en Taurus, en una edición a cargo de la hija del poeta, Soledad Vivanco. No es necesario insistir en que no se trata de unas memorias, sino de un diario íntimo que otra persona se ha encargado de seleccionar y editar. Al contrario que Aranguren, Laín y Ridruejo, Luis Felipe Vivanco tuvo una menor proyección pública y, de hecho, era el más oscuro de los componentes del grupo de Escorial. Todo esto tiene una importancia fundamental dentro del diario, pues, si bien su poesía llegó hasta altas cotas de calidad literaria, él se sabía un fracasado en el sentido profesional y su familia siempre anduvo escasa de dinero.

Lo interesante de este Diario es que nos acerca a un poeta que, aunque formaba parte del grupo descrito desde el primer momento, tuvo una vida perso- 
nal alejado del resto de componentes. Luis Felipe Vivanco no se ocupa en su diario de los años de la guerra, sino que pasa directamente a 1941 -empezó a escribir los diarios en ese año, pero la selección de su hija comienza en 1946, cuando su actividad intelectual es mayor-. Soledad Vivanco Gefaell informa de los pormenores de la edición del Diario en una nota previa, reproducida aquí parcialmente:

Este libro es un resumen del Diario que llevó mi padre, Luis Felipe Vivanco, de 1946 a 1971.

Cuando lo empezó tenía treinta y ocho años, hacía uno que se había casado, y siguió escribiéndolo hasta su muerte, aunque en los últimos años no trabajó mucho en él. Es un diario muy extenso; iba escribiéndolo en cuadernillos pequeños que llevaba siempre encima y que, pasados a limpio, ocupan unos cinco mil folios.

En esta primera aproximación he querido que el libro dé una idea general y lo más completa posible de cómo era él, pero sobre todo me ha parecido importante todo lo que se refiere a la creación y a su vida literaria. También he pretendido poner de relieve su actitud ante la España de su tiempo, y su forma de vivir el catolicismo. Dejo un poco de lado los "lugares vividos", los paisajes y la vida cotidiana, que son una parte muy importante del Diario. Y los últimos años, que fueron especialmente difíciles, y durante los cuales escribió las Prosas propicias, tampoco están bien reflejados aquí, porque escribió poco y además se autocensura, por problemas políticos. Quiero recordar muy especialmente a mi madre, María Luisa Gefaell, gran escritora y gran renunciadora. Dedicó los dos años que mediaron entre su muerte y la de mi padre a poner en limpio todo el Diario. Y, por tanto, este libro es una continuación de su trabajo (Vivanco, 1983: 9).

Como vemos, no estamos ante el diario íntegro de Luis Felipe Vivanco, sino ante una selección que ha llevado a cabo su hija, que nos entrega lo que ella considera más relevante para la dimensión literaria de su padre. Si bien es cierto que ha habido en nuestro país, durante el siglo XX, cierta profusión de libros de memorias y autobiografías, la verdad es que escasean bastante los diarios de carácter íntimo, como es este que ahora presentamos. Por eso, cuando este diario vio la luz fue bien recibido por la crítica. Jaime Siles, a quien ya hemos mencionado, sitúa el Diario de Vivanco al lado de los libros de memorias más importantes de su generación: «El Diario de Vivanco supone, además, un examen de conciencia de los paradigmas y circunstancias que conforman la Weltanschauung de su generación. En este sentido -y junto con las Memorias de Aranguren, las Casi unas memorias de Ridruejo, y el Descargo de conciencia de Laín- son un testimonio histórico de una honestidad incuestionable» (Siles, 1987: 156). Si había algo que emparentaba a todos estos autores era precisamente la idea de desengaño, desencanto o desilusión. Por eso, en sus libros dan cuenta de un fracaso, el de la reconstrucción intelectual iniciada con la aventura aperturista de Escorial. Sin embargo, su fracaso fue sólo relativo, y esto explicaría la propia evolución desde la militancia falangista hasta actitudes democráticas. 
El Diario está dividido por años y la última entrada corresponde a 1975. Desde el primer momento, encontramos a lo largo de todo el texto una continua reflexión sobre la poesía en general y sobre su escritura poética en particular, que viene definida en estos términos en un apunte de 1946: «Incapacidad para interesarme de veras o emocionarme, ni poética ni humanamente, con las cosas públicas, es decir, con la política. Sentimientos íntimos como refugio contra el mundo. Este ha sido siempre el núcleo temático de mis poemas» (Vivanco, 1983:18). En apenas tres líneas, Vivanco define la tan traída poesía de la intrahistoria o poesía arraigada, y que, en realidad, es aquella que busca consuelo y refugio en las realidades más cotidianas e íntimas -Dios, la casa y la familia, entre otros temas-. Como ya se ha dicho, esta poesía tiene a uno de sus mejores cultivadores en el propio Vivanco, pero también en Luis Rosales y Leopoldo Panero, amigos íntimos del poeta.

La armonización de la vida con la obra, una de las máximas preocupaciones de Vivanco, es uno de los motivos recurrentes en su escritura diarística. Como no es profesionalmente un poeta, sino un arquitecto, considera que la poesía forma parte de su vida, pero reconoce que no debe perderse la vida sólo para conseguir una mayor producción. Ésta es una de sus mayores cuitas, sobre todo en él, que había de volver eventualmente a la arquitectura para poder subsistir:

Esto es sólo vida. Pero es más importante vida que obra. Y sin embargo, tengo que dejar obra. Pero ¿cómo salir de la vida? ¿Perderme vida por culpa de la obra? Eso estaba bien de soltero.

Uno de los momentos más significativos de este Diario es cuando, tras haber asistido a una lectura de La casa encendida, de su amigo Rosales, Vivanco reflexiona sobre la obra maestra del poeta granadino y la vincula con otros libros de la misma generación, como La estancia vacía de Leopoldo Panero:

\footnotetext{
Luis ha recitado en el Aula Poética del Ramiro de Maeztu su poema La casa encendida. La soltería solitaria en las habitaciones de su casa. Su dormitorio, sus muebles, su cama. Y, de pronto, una luz que se enciende en el cuarto trastero, a través del patio. La marcha hacia esa luz. Está allí Juan Panero. Y recuerda los días de la Facultad: sale Piedad, salen Pilar, Concha, María Josefa, María Dolores. Salgo yo. "Presupuestario y ejemplar" me llama. Y cuando se apaga esta luz y vuelve a su dormitorio, en el despacho pequeño, otra luz encendida. Lluvia, puerto de mar, embarcadero. Barca de remos que se acerca. Una figura de mujer, de colegiala. Una interrupción. Un timbre. ¿Es un timbre o una sirena? Es el médico de una sociedad. Sigue el poema: la descripción de Maruca, que se queda también en el pasado. Y otra habitación que se enciende: su biblioteca, los libros que caminan y caminan. Hablando de él. Son sus padres muertos. Su primer Corpus y las campanas de Granada sonando a Corpus... Al día siguiente, al volver a su casa, desde la calle, la ve toda encendida. Y le da gracias a Dios por ello. El poema es hermoso, vivido, vivo, dinámico, sin fallos, de un tirón. Alegre y juguetón de lenguaje, de elementos. Es un gran poema. Aún no lo he leído despacio. Tendré que hacerlo. Está en la línea de La estancia vacía, de mi
} 
Invierno, de Los ángeles diarios de Fernando Gutiérrez. Con más elementos imaginativos concretos y más acierto natural de expresión. Menos posado y grave que el de Leopoldo, menos concentrado y realista que el mío (Vivanco, 1983: 51).

En un apunte de 1954, Vivanco se refiere a dos de sus compañeros de generación tempranamente desaparecidos, Juan Panero Torbado y Miguel Hernández, sobre los cuales está preparando una conferencia. Esto es lo que dice sobre su poesía:

Estoy leyendo poemas de Juan Panero para la conferencia del miércoles. ¡Qué voz honda, ahondada hasta lo increíble, aislada, exhausta en sí misma sin llegar a la aridez, ni a la monotonía! Poemas sin hacer, pero con voz auténtica y purísima de soledad de hombre. Escritos desde la soledad más verdadera. Y con el dolor ahondado en la soledad. ¡Qué sobrios y sin estropear en su arranque, en su vibración de alma desnuda! Pocas veces se ha expresado tan sin otros recursos el alma. Poesía amorosa, pero lo contrario a La voz a ti debida, de Salinas. Escrita desde otros estratos del corazón. Miguel Hernández y Juan, son dos poetas altísimos, pero sobre todo, humanísimos, en los que la poesía contemporánea española alcanza ese tono de humanidad a cuerpo limpio que va a perdurar hasta hoy en sus voces mejores. Para mí, algunos de estos poemas tienen todavía mayor emoción, porque recuerdo los momentos en que los escribíamos juntos. Juntos, sí, pero con la voz de Juan. Poemas de amor y de muerte. De aceptación de la muerte desde lo hondo de la soledad vivida (Vivanco, 1983: 77).

Por otro lado, la vida en la ciudad siempre fue para Vivanco una suerte de suplicio, ya que no podía trabajar ni escribir, al necesitar constantemente la tranquilidad y la belleza del campo, el refugio en lo humilde. Él se sabe diferente de sus amigos, «siempre seré oveja negra, al margen» (Vivanco, 1983: 78), ya que ellos se sienten atraídos por las luces de la ciudad y de la cultura más o menos establecida "oficialmente», según esta anotación de 1953: «Qué felices Luis y Dionisio, que pertenecen más a la ciudad y a la cultura!» (Vivanco, 1983: 78). Del mismo modo, Vivanco duda acerca de si es un buen poeta, pues nunca gozó de tantos honores como sus compañeros. Le atormenta pensar que su poesía puede ser mediocre, y que, en realidad, no lo tienen en cuenta precisamente por eso:

¿Por qué mi destino consiste en ser poeta mediocre y sufrir tanto? ¿Tendré que reconocerlo, por fin? ¿Habré vivido engañado hasta ahora? ¿Qué es mi obra comparada con la de los demás? Hasta ahora, seguro de mí mismo, he despreciado el que no me tuvieran más en cuenta, pero ¿tendrán razón, Dios mío? ¡Si ni siquiera te tengo a ti! ¡No tengo la forma! ¡Hay que apurar el cáliz! Y que quiera a mis hijos y los saque adelante. ¡Lo mejor para ellos! (Vivanco, 1983: 86).

En ocasiones, también hay espacio en estas hojas para la reflexión política y para la mala conciencia por haber apoyado la causa de Franco durante la Guerra Civil. Así, por ejemplo, esta reflexión la encontramos justo después de la noticia de que han detenido a Dionisio Ridruejo: 
¿Por qué soy católico de izquierdas? Desarrollar este tema para los seminaristas. Soy católico de izquierdas porque creo que la Biblia es un libro maravilloso (los católicos de derechas no leen la Biblia). Y porque creo en el Renacimiento y en la supremacía moral suya sobre la Edad Media. Y porque estoy al lado de Copérnico y Galileo, y de todos los investigadores serios e imaginativos, incluso Darwin o Renan. El libro sobre el Origen de las especies me parece equivocado pero admirable como testimonio humano. Y porque creo que Fray Luis, San Juan de la Cruz o Santa Teresa tenían razón contra los perseguidores. Y porque creo que San Ignacio tenía razón fundando en Montmartre la Compañía que no le dejaron fundar ni en Alcalá ni en Salamanca. Y porque la Revolución Francesa me alegra la sangre y me alegra que terminara con el Antiguo Régimen y todas sus brutales injusticias. Y porque creo que no existe ningún motivo para que el catolicismo español no sea un catolicismo creador. Y sobre todo, porque además de en el cielo y en la otra vida, sueño con las maravillas del mundo submarino. Y cuento con ellas. Y contar con ellas me parece la más hermosa y poética razón para ser católico de izquierdas (Vivanco, 1983: 96-97).

En otro momento, carga las tintas contra el régimen, hasta el punto de afirmar que «[t] odo lo que tiene calidad en España es antifranquista (pero no anticatólico)» (Vivanco, 1983: 102), y aquí aparece el eterno tema del problema de España, del que tanto se había ocupado Laín Entralgo:

El problema de España y de los españoles es un problema de mala digestión. Todavía no han podido digerir al liberalismo, ni a Unamuno, ni a Ortega, ni siquiera a Juan Ramón Jiménez. Y no digamos a Picasso o a Joan Miró. Tenemos el estómago político-religioso estragado, y nos sienta mal incluso demasiado San Juan de la Cruz o católicos franceses.

Esto lo vio muy bien Antonio Machado. En este sentido, escribir en España debe consistir en no quedarse en Pemán o en Sánchez Mazas, que son el límite de lo que digieren los más preparados. El tradicionalismo español no digiere lo verdaderamente tradicional nuestro: Arcipreste o Cervantes, pero tampoco Altamira o Goya. Y el franquismo actual no digiere a la generación del 98. Por otra parte, los estómagos de nuestros obispos y, en general, autoridades eclesiásticas, pertenecen todavía a un estado de antropofagia espiritual (Vivanco, 1983: 122).

Toda la existencia de Luis Felipe Vivanco se debate en estos mismos términos. Otro hito interesante dentro de su Diario es la muerte de Leopoldo Panero, lo que le obliga a desplazarse hasta Astorga para asistir a su entierro. Al morir Leopoldo, Vivanco le escribe una carta a Juan Panero, muerto en 1937, que es uno de los mejores homenajes que jamás se le hayan escrito a los hermanos Panero. Al contrario que las memorias de sus compañeros de generación, todo el Diario de Vivanco es intimidad de un alma en lucha constante consigo misma. No resulta gratuito que uno de sus mejores poemas sea precisamente la «Elegía de Cervantes», donde elogia al maestro fracasado. Él es consciente de no estar a la altura del maestro y de no merecer ese título, pero se le asemeja en ese fracaso vital que los ha unido a través de los siglos: «No hace falta haber triunfado en toda la línea (Cervantes, el gran fracasado)» (Vivanco, 1983: 206).

Anales, 21, 2009, pp. 85-99 
En cierto modo, a Luis Felipe Vivanco se le puede tildar de exiliado interior, sobre todo por su situación con respecto a sus compañeros de generación. Perteneció a aquella intelectualidad de la España vencedora, pero pronto llegó el desengaño y con ella sólo compartió la amistad y las colaboraciones en revistas como Escorial. A pesar de todo, es una de las voces más genuinas de la poesía de nuestro siglo. En este sentido, resulta especialmente doloroso para Vivanco reconocer su fracaso a la altura de 1973, apenas dos años antes de su muerte:

\footnotetext{
Si miro hacia atrás, veo que toda mi vida de casado - desde el año 45 hasta hace unos meses- ha sido una continuada y absurda angustia económica, sin apenas compensaciones de orden literario. Una vida, no fracasada, sino más bien equivocada. Y la culpa ha sido de mi profesión de arquitecto. Con la literatura o poesía, nada más, hubiera vivido pobre. Pero con la arquitectura he vivido, además, maniatado. He trabajado, no sé si mucho o poco, pero sin provecho. No he tenido -en arquitectura y en literatura- más que migajas. Y esto, prescindiendo de la dimensión política del asunto, que lo empeora (Vivanco, 1983: 233).
}

La sinceridad que encontramos en el texto de Vivanco no es común. Tengamos en cuenta que estamos ante un texto de carácter íntimo que probablemente no pensara publicar. Del mismo modo, su testimonio da cuenta de esa desilusión de la que hemos venido hablando, pero, en su caso, vivida de una forma más radicalizada. De alguna manera, este diario puede ser considerado como el de todos los miembros del grupo, aunque bien es cierto que los otros, al contrario que Vivanco, se refugiaron en la oposición política -en el caso de Ridruejo- y en la actividad académica -en el caso de Pedro Laín- o editorial -en el caso de Panero y Rosales-. Vivanco quedó a solas consigo mismo, lo que le permitió reflexionar sobre las lecturas, la vida pasada, el falso cristianismo y, sobre todo, la poesía, la suya, la de sus amigos y la de los maestros: Unamuno, Machado, Neruda, Vallejo, Juan Ramón... ¿Una vida fracasada? Ni como persona ni como poeta. Como intelectual, quizá, pues Vivanco renunció desde el principio a la dimensión pública del intelectual.

En cuanto a Los cuadernos de Segovia, se encuentran estrechamente relacionados con los textos del Diario, pues se trata de una selección temática de los textos de los mencionados blocs, concretamente los que se escribieron en la ciudad de Segovia. Los veranos era el momento del año que Vivanco aprovechaba para regresar a la naturaleza, tan presente en su poesía. Afortunadamente, gracias a los desvelos de María Luisa Gefaell y Luis Martínez Drake, conservamos fragmentos de los cuadernos escritos en los veranos segovianos de los años 1955, 1959, 1960 y 1962. Como señala el propio Martínez Drake, «[e]ste libro trata del acercamiento intrahistórico a la realidad de Segovia, desvestida por tanto de todo lo que en su historia no es el hombre, o no es Naturaleza y Espíritu» (Vivanco, 1991: 11). Ya en las primeras páginas, Vivanco se sitúa, toma partido ante una 
realidad que le disgusta, la de la España que le ha tocado vivir y la de la situación económica por la que está pasando su familia:

Vivimos un poco sucios, mal vestidos y planchados, improvisando cada día a la bohemia. En casa con suelos sin fregar, que nos sobran por todas partes. Pero sin rendirnos al Opus ni a las derechas ni al Movimiento. Vivimos con intensidad de independencia espiritual. Ah, si pudiéramos crear, María Luisa y yo. Qué cosas saldrían. La sociedad se defiende no dejándonos crear. Aumentemos las distancias. Ustedes allí y nosotros aquí (Vivanco, 1991: 31).

En este volumen, sin embargo, el protagonismo ya no recae tanto en el propio autor como en la ciudad de Segovia, espacio privilegiado para leer, escribir y pasear, frente a la atmósfera agobiante que es Madrid para Vivanco, según vimos. En 1959, prepara una conferencia sobre su propia poesía que resume en sus cuadernos con las siguientes palabras:

Mi lectura en San Quirce. Divido mi trayectoria poética en cuatro etapas: $1^{\circ} \mathrm{Me}$ moria de la plata. Palabra imaginista, brillante, ¿futurista? Influencia de Alberti, de Rimbaud y de Apollinaire. $2^{\circ}$ Tiempo de dolor, Cantos de primavera, Baladas interiores. Versículo largo y ceñido a su contenido. Influencia de Claudel. $3^{\circ}$ Paso de mi vida de soltero a la de casado, y de mi palabra más enfática a otra más sencilla: Los Caminos, libro de transición, sin publicar. Continuación de la vida y El Descampado, libros en que logro mi palabra más mía y definitiva. Cancionero de Loredo, libro en que me aligero, de coplas y estribillos. $4^{\circ}$ Los Coloquios, los Poemas con la muerte, los Poemas plásticos (Vivanco, 1991: 138).

De nuevo surge la idea del fracaso, auténtico leitmotiv en la existencia de Vivanco. La anotación es de junio de 1960:

En su Cervantes y la libertad, y en su capítulo final, Luis [Rosales] nos habla del fracaso. Lo humano es fracasar. En Cristo hay fracaso humano, si también logro divino. En mis Lecciones hay fracaso. En el fondo, su libro y el mío están escritos en el mismo tono, aunque la forma sea distinta. Más ensayística e intelectual en él, más lírica en mí. Fracasa Don Quijote para humanizarse y fracasan el príncipe y Charlot. Mi Descampado es libro de fracaso (Vivanco, 1991: 162).

Al final, la sensación que tiene el lector del Diario y de los Cuadernos es que se ha asomado tan sólo a un patio de un enorme palacio que ha podido ver en la distancia. Ha podido contemplar el estilo y una mínima parte del contenido, pero todavía le queda mucho por conocer. Así, en los Cuadernos únicamente se seleccionan unos meses determinados de unos años concretos, pero ésos podemos conocerlos más detalladamente, de forma más cercana. En el Diario, en cambio, se dosifican treinta y cuatro años enteros, lo que da un panorama mucho más abarcador y, por tanto, más fragmentado. Los Cuadernos son algo así como un primer plano sobre las libretas autodiegéticas de Vivanco, mientras que el Diario ofrece un plano general. Y lo mejor de todo, o al menos lo más interesante, es que ese monumento a la memoria todavía espera a un editor intrépido

Anales, 21, 2009, pp. 85-99 
que consiga la confianza y la complicidad de los herederos. Hasta que llegue ese momento, tendremos que conformarnos con estos dos volúmenes, más importantes por lo que anuncian o prometen que por lo que ofrecen.

\section{BIBLIOGRAFÍA}

ALARCÓN SIERRA (2007), Rafael, Luis Felipe Vivanco: contemplación y entrega, Madrid, Ayuntamiento de Madrid.

ALONSO, Dámaso (1979), «Dos lecturas de Luis Felipe Vivanco», Nueva Estafeta, núm. 2, pp. 47-53.

- (1957), Pról. a Luis Felipe VIVANCO, El descampado, Palma de Mallorca, Col. Juan Ruiz.

ARANGUREN, José Luis L. (1957), Crítica y meditación, Madrid, Taurus, 1977.

- (1969), Memorias y esperanzas españolas, Madrid, Taurus.

BLEIBERG, Germán (1950), «Luis Felipe Vivanco. Continuación de la vida», Clavileño, núm. 2, pp. 68-69.

CABALlÉ, Anna (1996), «Ego tristis (el diario íntimo en España)», Revista de Occidente, núms. 182-183, pp. 99-120.

— 2007, «Vivanco, épica de un diario», ABC De las artes y las letras, núm. 804, 30 de junio de 2007, pp. 10-11.

CANO, José Luis (1975), «Luis Felipe Vivanco», Ínsula, núm. 349, 4-5.

- (1984), «Luis Felipe Vivanco: Diario, 1947-1974», Ínsula, núm. 447, pp. 8-9.

FERNÁNDEZ ROCA, José Ángel (2001), «La palabra vivida. Aproximación a Luis Felipe Vivanco y su poesía», en Luis Felipe VIVANCO, Obras I. Poesía I, Madrid, Trotta, pp. 9-82.

IRAVEDRA, Araceli (2001), El poeta rescatado. Antonio Machado y la poesía del"grupo Escorial", Madrid, Biblioteca Nueva.

JUAN PENALVA, Joaquín (2000), «Descargos, diarios y palinodias: algunos ejemplos de literatura memorialística en la generación del 36», Anales de Literatura Española. Memorias y autobiografías, edición de Ma Ángeles AYALA ARACIL, núm. 14, pp. 97-133.

- (2005), «Magister inter iuvenes: Eugenio d'Ors y los intelectuales falangistas de Escorial», en ARDAVÍN, Carlos X., Eloy E. MERINO y Xavier PLA (eds.), Oceanografía de Xènius. Estudios críticos en torno a Eugenio d'Ors, Kassel, Reichenberger, pp. 75-85.

- (2004), «Miguel Hernández y otros poetas del 36 en los años de la Segunda República», en Juan José SÁNCHEZ BALAGUER y Francisco ESTEVE 
RAMÍREZ (eds.) y Aitor L. LARRABIDE (coord.), Presente y futuro de Miguel Hernández. II Congreso Internacional Miguel Hernández, Orihuela/Universidad Complutense, Orihuela, Fundación Miguel Hernández, pp. 401-412.

- (2002), «Tres poetas del 36 en El Gallo Crisis: Félix Ros, Luis Felipe Vivanco y Luis Rosales», Alquibla. núm. 8, pp. 553-572.

- (2001), «Un grupo de poetas amigos': Los autores del realismo cotidiano en Veinte años de poesía española», en Eduardo A. SALAS ROMO (ed.), De sombras y de sueños. Homenaje a J. M. Castellet, Barcelona, Península, pp. 186-199.

LÓPEZ CASTRO, Armando (2000), «La lección trascendente de Luis Felipe Vivanco», en Memoria de un olvido. Poetas de un Tiempo Menesteroso, León, Universidad de León, pp. 41-69.

SILES, Jaime (1987), «El Diario de Luis Felipe Vivanco», Cuadernos Hispanoamericanos, núm. 442, pp. 154-157.

UMBRAL, Francisco (1984), Trilogía de Madrid. Memorias, Barcelona, Planeta.

VALVERDE, José María (1958), «La humildad de ser poeta (Sobre Continuación de la vida, de Luis Felipe Vivanco)», en Estudios sobre la palabra poética, Madrid, Rialp, pp. 189-201.

VIVANCO, Luis Felipe (1950), «Aproximándome a la poesía temporal y realista», Proel, VI, primavera-estío de 1950, pp. 17-27.

- (1983)Diario 1946-1975, Madrid, Taurus.

- (1971) Introducción a la poesía española contemporánea, 2 vols., Madrid, Guadarrama.

- (1961) Lecciones para el hijo (Poemas), Madrid, Aguilar.

- (1974) Los Caminos (1945-1965), Madrid, Cultura Hispánica.

- (1998) Los caminos (Antología), Madrid, Visor.

- (1991) Los cuadernos de Segovia (Estancias y vagancias) (Veranos de 1955, 1959, 1960 y 1962), Segovia, Diputación Provincial de Segovia.

- (1953) Los ojos de Toledo. Leyenda autobiográfica, Barcelona, Barna.

- (1958) Memoria de la plata, Madrid, Rialp.

- (1972) Moratín y la Ilustración mágica, Madrid, Taurus.

- (2001) Obras. Poesía, ed. de Pilar Yagüe y José Ángel Fernández Roca, 2 vols., Madrid, Trotta.

— (1940) Tiempo de dolor. Poesía 1934-37, Madrid, Silverio Aguirre.

Fecha de recepción: 3 de junio de 2008

Fecha de aprobación: 6 de octubre de 2008 